\title{
Nostalgia and the town inside pictures
}

\author{
Tam-Tri Le \\ Centre for Interdisciplinary Social Research \\ Phenikaa University, Hanoi, Vietnam \\ Written in Ho Chi Minh City on 5 July 2021 \\ OSF Preprints, DOI: 10.31219/osf.io/hd7vq
}

Sometimes, when viewing an old photo, listening to an old song, or encountering a subtle fragment of the long-gone past, we can suddenly be hit hard and heavy with immense nostalgia. But it is not only a mysterious melancholic vibration for those who have lived through the experience. People also can have a strange feeling of longing for the place and time they have never been in, be it fictional or not. This feeling is subjectively vague and difficult to describe, or even shaped into a concept. In English, some call it saudade (borrowed from Portuguese) or sehnsucht (borrowed from German) or casually just "false nostalgia". However, it seems that words could not fully capture the sensation and all the complex emotions it brings.

A couple of years ago, a group of my colleagues and some others conducted quite an interesting research. They tried to find the expression of cultural evolution in northern Vietnam's architecture, particularly the house façade of the Old Quarter in Hanoi city (Vuong et al., 2019). The beautiful Indochine style of the early $20^{\text {th }}$ century did not simply stay the same but moved through time and changed in alignment with corresponding historical events. Evidence from the study showed a dynamic shift of designs and patterns with a mixture of influences from the French and Chinese culture and Buddhism values into traditional Vietnamese elements. This is one of the easily observable aspects of the multifaceted cultural additivity phenomenon (Vuong et al., 2018). The study also showed the effectiveness of utilizing Bayesian statistics in examining cultural evolution.

Here I would like to mention that one of the authors of that research is Mr. Bui Quang Khiem - a professional artist (painter) - who for more than ten years had taken over 500 pictures of old houses in Hanoi city (which were used as resources to create data lines for the study's analysis). Some of the authors in the group, including Mr. Bui Quang Khiem, have themselves lived and seen the changes of Hanoi city over the late decades of the $20^{\text {th }}$ century. Not just understanding from scientific data, these people have directly experienced the flow of time and the transformation of the very town they have always known. Even when buildings might stay longer than the people who made them and lived the living culture of the past, eventually they too will change with the flow of time. And when their last generation is to answer the call of fate, all the lively memory will stay as a beautiful shade in the pictures, songs, and stories for the young to explore and wonder. 


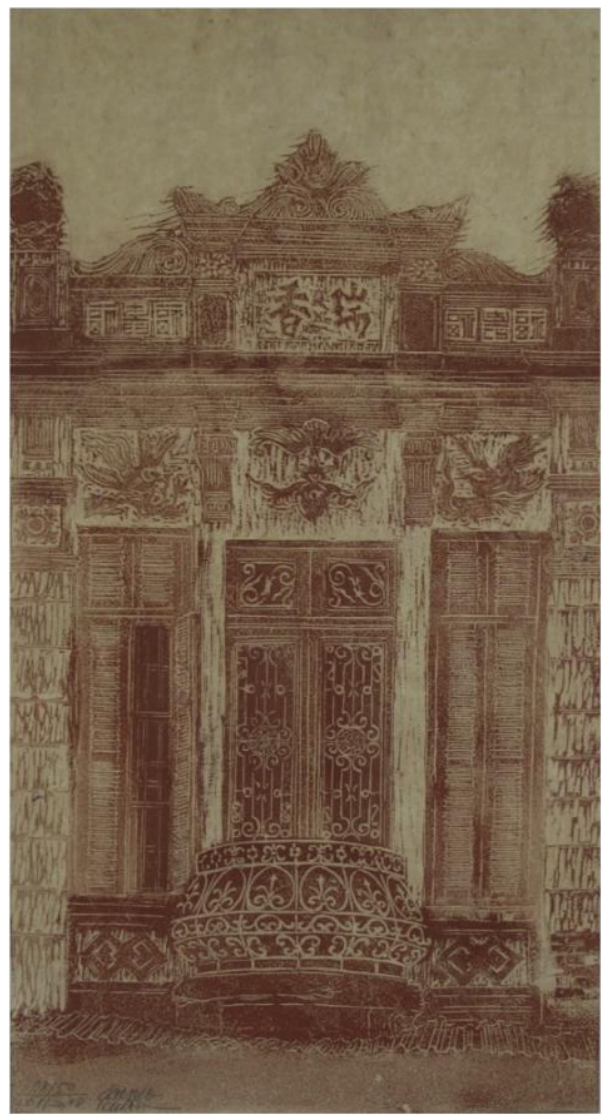

The painting on the left was made by Mr. Bui Quang Khiem, as presented in the original paper "Cultural evolution in Vietnam's early 20th century: A Bayesian networks analysis of Hanoi Franco-Chinese house designs "(Vuong et al., 2019).

I belong to the new generation who never lived in that world of the long-gone time. But it is the eternal beauty of art that can make people nostalgic for the unfamiliar faraway place. And the indescribable feeling of accepting that as a human I would never be able to truly know something right in front of my eyes is an enigmatic melancholy.

Last night I listened to "La gata bajo la lluvia" by Rocío Dúrcal and again that feeling arose for me to tell myself that maybe deep within the universal impermanence, humans are likely the special beings that have got a glimpse of the essence of eternity.

\section{References}

Vuong, Q.-H., et al. (2019). Cultural evolution in Vietnam's early 20th century: A Bayesian networks analysis of Hanoi Franco-Chinese house designs. Social Sciences \& Humanities Open, 1(1), 100001. https://doi.org/10.1016/j.ssaho.2019.100001

Vuong, Q.-H., et al. (2018). Cultural additivity: Behavioural insights from the interaction of Confucianism, Buddhism and Taoism in folktales. Palgrave Communications, 4, 143.

https://doi.org/10.1057/s41599-018-0189-2 